\title{
RESTORING FRACTURED ANTERIOR TEETH USING FIBRE REINFORECED COMPOSITE POST: CASE REPORTS
}

\author{
N. Sukumar Singh ${ }^{1}$, N. Satish Kumar Singh ${ }^{2}$, Pinky Thangjam ${ }^{3}$
}

\section{HOW TO CITE THIS ARTICLE:}

N. Sukumar Singh, N. Satish Kumar Singh, Pinky Thangjam. "Restoring Fractured Anterior Teeth using Fibre Reinforced Composite Post: Case Reports". Journal of Evolution of Medical and Dental Sciences 2014; Vol. 3, Issue 31, July 31; Page: 8674-8681, DOI: 10.14260/jemds/2014/3105

\begin{abstract}
Traumatized anterior teeth require quick, functional and esthetic treatment so as to avoid patient from psychological trauma. The prosthetic treatment of seriously damaged, endodontically treated teeth often require an endodontic post as an additional retention element for core build up prior to crown restoration. Fractured anterior teeth can be best restored using a post and core after endodontic treatment. In this article, cases are shown how fractured anterior teeth are restored using fibre reinforced composite post.
\end{abstract}

KEYWORDS: fractured tooth, endodontic post, Ellis class III fracture, ceramic crown.

INTRODUCTION: In permanent dentition, the most common types of trauma occur in the maxillary incisor region and could cause crown fractures.1,2 Traumatized anterior teeth require quick, functional and esthetic treatment ${ }^{3}$ so as to avoid patient from psychological trauma. Fractured anterior teeth can be best restored using a post and core after endodontic treatment. Many types of post are available for the restoration of endodontically treated teeth. ${ }^{4}$

Post composition varies considerably today and includes metal of various types, fibrereinforced composite, carbon fibres held together with epoxy resin and ceramic. In the following case reports, fibre-reinforced composite post was the choice as the fibre-reinforced resin-based composite posts are superior to metal prefabricated posts. They are tooth coloured and do not impart a grey colour to the remaining tooth. Additionally, they are easy to place, are relatively inexpensive, can be bonded to resin cement and are easy to remove if the tooth needs to be retreated endodontically.

CASE 1: A 23 years old male patient was reported to the Department of Dentistry, Jawahar Lal Nehru Institute of Medical Sciences, Imphal with the complaint of road traffic accident. Extraoral examination revealed lacerated upper lips on the left side. Intraoral examination showed Ellis class III horizontal fracture of left central and lateral incisor at the level of cervical third (Fig. 1). Occlusion was normal and no other abnormalities were detected. Patient was given first aid treatment with suturing of the lacerated wounds and referred for radiographic reports.

Intra Oral Periapical X-ray of 21 and 22 showed horizontal fracture with pulpal involvement (Fig. 2). Treatment planning was done as follows. First removal of fractured crown portion and endodontic treatment of the fractured incisor followed by restoration of the crown using post and core.

Treatment was started with removal of fractured crown portion under local anesthesia. A single sitting root canal treatment was done in both incisors (Fig. 3, 4). Patient was given antibiotic coverage and analgesic.

The patient was recalled after a week and post space preparation was done. In this case, fibrereinforced composite resin posts were used (Fig. 5). Cementation of glass fibre-reinforced composite 
resin posts in incisors were performed and composite resin build-up were done to restore the missing crown portion of the incisors. Crown lengthening was done using Diode Laser (Fig. 6). Tooth preparations were done for placement of ceramic crowns prosthesis. Impressions were made using polyvinyl siloxane impression material and send to dental laboratory for fabrication of ceramic crowns prosthesis. Patient was recalled after 3-4 days for restoration of the tooth by ceramic crown prosthesis.

CASE 2: A 36 years old female patient reported to the Department of Dentistry, Jawahar Lal Nehru Institute of Medical Sciences, Imphal with the complaint of fractured front teeth while chewing food two days back. Intra-oral examination showed Ellis class III fracture of 21 (left upper central incisor) at the level of cemento-enamel junction (Fig. 8). IOPA-X ray showed no infections at the apical region (Fig. 9).

Treatment planning was decided to restore the tooth with fibre- reinforced composite resin post and core ceramic crown after root canal treatment. Patient was put under antibiotic coverage and also advised to take analgesic if needed. Root canal treatment (Fig. 10) was done. After a week, post space was prepared using post preparation kit. Post length was approximately $2 / 3^{\text {rd }}$ of the length of the root of the incisor which will help in better retention of the fibre post with the root of the incisor. Cementation of glass fibre-reinforced composite resin posts in the central incisor was done using type II GIC Cement.

Composite resin build-up was done (Fig. 11,12) to give a proper support for the incisor to hold the ceramic crown prosthesis. Tooth preparation was done as indicated for ceramic crown. Alginate Impressions were made and send to dental laboratory for fabrication of ceramic crown prosthesis. Patient was recalled after 4 days and cementation of ceramic crown fixed prosthesis was done thus normal function and esthetic was restored (Fig. 13).

CASE 3: A 32 years old male patient was reported to the Department of Dentistry, Jawahar Lal Nehru Institute of Medical Sciences, Imphal with the complaint of fractured front teeth on a road traffic accident 2 weeks back and desire to restore it as it was not socially appealing. On intra oral examination, 12 (right upper lateral incisor) showed Ellis class III fracture at the level of cementoenamel junction (fig. 14) with necrotised pulpal tissue. Patient did not complain of any pain or tenderness when examined. IOPA-X ray showed no infections at the apical region (Fig. 15).

Treatment planning was decided first to treat the root canal of the fractured tooth and restored it with fibre- reinforced composite resin post and core ceramic crown. Root canal treatment was done on the same day (Fig. 16) under antibiotic coverage. Patient was recalled after 5 days and post space was prepared using standard post preparation kit. Cementation of glass fibre-reinforced composite resin posts in the lateral incisor was done using type II GIC.

Composite resin build-up was done (Fig. 17, 18) to support the fixed ceramic crown prosthesis. Tooth preparation was done as indicated for ceramic crowns prosthesis. Impressions were made and send to dental laboratory for fabrication of ceramic crown prosthesis. Patient was recalled after a week and ceramic crown prosthesis was cemented (Fig. 19).

CASE 4: An 18 years old female patient reported to the Department of Dentistry, Jawahar Lal Nehru Institute of Medical Sciences, Imphal with the complaint of fractured front teeth on a road traffic 
accident 1 week back and desired to restore it as it was not socially appealing. On intra oral examination, 21 (left upper central incisor) had an Ellis class III fracture at the level of gingival 1/3 rd (Fig. 20, 21) with exposed pulpal tissue.

Treatment planning was done as follows, endodontic treatment of the fractured incisor and then restoration of the crown using post and core.

Patient was advised antibiotic and analgesic for 5 days and advised to report after 3 days.

On the recalled day, endodontic treatment was started under local anesthesia in the fractured central incisor which continued for 3-4 recalled visits. After completion of root canal therapy patient was advised to revisit after a week

Patient reported after 7 days and post space was prepared using standard post preparation kit on the root canal treated tooth. Fibre post was the choice for the post inserted. Cementation of glass fibre-reinforced composite resin posts in the central incisor and composite resin core build-up was done to support the ceramic crown prosthesis (Fig. 22). Tooth preparations were done as indicated for ceramic crowns and ceramic crown was cemented after a week when the prosthesis was delivered from dental laboratory (Fig. 23, 24).

DISCUSSION: The healthy oral cavity is a primary requisite for beautiful looks. Patients with fracture anterior teeth suffer not only medically but also psychologically. Immediate restoration of the missing tooth structure is the prime requisite. ${ }^{1}$ Fractured or broken anterior teeth are best restored using post and core restoration with ceramic crowns. ${ }^{5}$ Posts may be constructed of a variety of materials, including resin composite, metal, and biologic material. ${ }^{3}$ In recent years, various types of fibre reinforcement have come into widespread use as an alternative to cast or prefabricated metal posts in the restoration of endodontically treated teeth.

The advantages of using reinforced fibre to construct an intracanal post include resin composite crown reinforcement, translucency, and relative ease of manipulation. Evidence for the clinical success of fiber posts when restoring endodontically treated teeth has been reported. Mannocci and co-workers ${ }^{6}$ compared restoring endodontically treated premolars with fiber posts and composite resin cores to restorations of premolars with amalgam.

Treating 109 premolars, at the 5-year recall they found that restorations with fiber posts and composite were found to be more effective than amalgam in preventing root fractures but less effective in preventing secondary caries.

The advantages of using reinforced fiber to construct an intracanal post include resin composite crown reinforcement, translucency, and relative ease of manipulation. It also has greater flexural strength (1280 MPa), greater ease of handling, can be used in high stress bearing areas and can be bonded to any type of composites. As it was relatively ease of manipulation and its translucency nature gave operator to create a life like prosthesis.

All the restored teeth were both esthetically and functionally stable, giving all the patients confident at social appearance. Malferrari ${ }^{7}$ restored 180 endodontically treated teeth using fiber posts with a composite-resin core and, subsequently, all-ceramic crowns. At the 30-month recall, $1.7 \%$ of the restorations had failed due to the crown but no post, core, or root fracture was recorded.

CONCLUSION: For the case presented, a fibre post meets both the esthetic and restorative needs for the clinical situation. To avoid disastrous consequences of root fracture and tooth loss, the fibre 
reinforced resin post, offers a safer alternative to metal or ceramic posts- Fibre reinforced posts are energy dissipating when compared to the energy transmittance of more rigid metal and ceramics that might be used as post materials that would put the tooth root at risk.

Fibre posts have a definite place in a restorative dentist's armamentarium. When restoring an endodontically treated tooth, treatment planning for the use of a fibre post should be based upon the clinical needs of the case. Also, to achieve good clinical success, the clinician must choose compatible materials and techniques for cementation when using a fibre post, and be assured that the crown preparation for the tooth has an adequate ferrule.

\section{REFERENCES:}

1. Lam R, Abbott P, Lloyd C, Kruger E, Tennant M. Dental trauma in an Australian rural centre. Dent Traumatol. 2008; 24 (6): 663-70.

2. Sandalli N, Cildir S, Guler N. Clinical investigation of traumatic injuries in Yeditepe University, Turkey during the last 3 years. Dent Traumatol. 2005; 21 (4):188-94.

3. S. M. Sholapurmath, S. Anand. Use of polyethylene fiber in pediatric esthetics clinical reports of two cases. Journal of International Oral Health. 2010; 2 (2): 99-102.

4. Iglesia-Puig MA, Arellano-Cabornero A. Fiber-reinforced post and core adapted to a previous metal ceramic crown. J Prosthet Dent. 2004; 91 (2): 191-4.

5. Ozel E, Kazandag MK, Soyman M, Bayirli G. Two-year follow-up of fractured anterior teeth restored with direct composite resin: report of three cases. Dent Traumatol. 2008; 24 (5): 589-92.

6. Mannocci F, Qualtrough AJ, Wrothington HV, et al. Randomized clinical comparison of endodontically treated teeth restored with amalgam or with fiber posts and resin composite: five-year results. Opera Dent. 2005; 30 (1): 9-15.

7. Malferrari S, Monaco C, Scotti R. Clinical evaluation of teeth restored with quartz fiberreinforced epoxy resin posts. Int J Prosthod. 2003; 16 (1): 39-44.

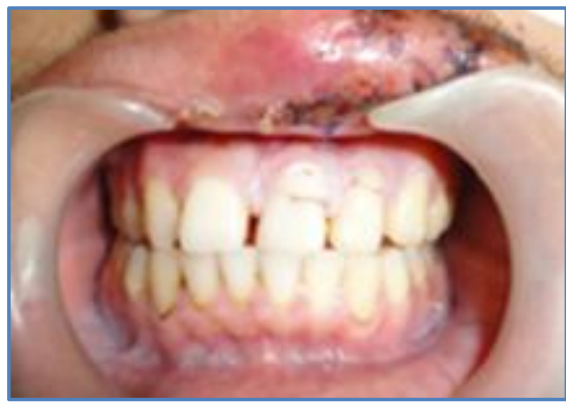

Fig. 1: Fractured anterior teeth (pre-operative)

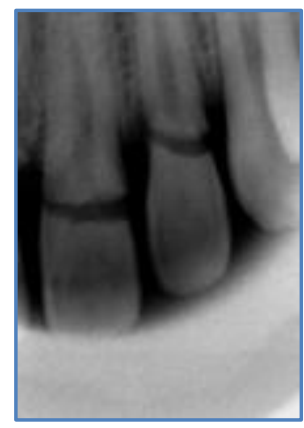

Fig. 2: Pre-operative $x$-ray showing fractured at cervical third 


\section{CASE REPORT}

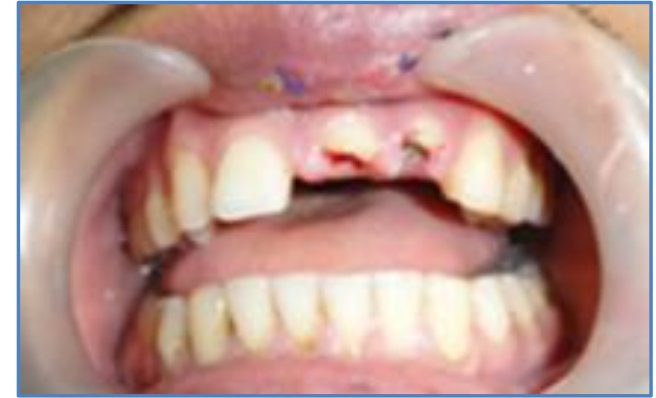

Fig. 3: After root canal treatment

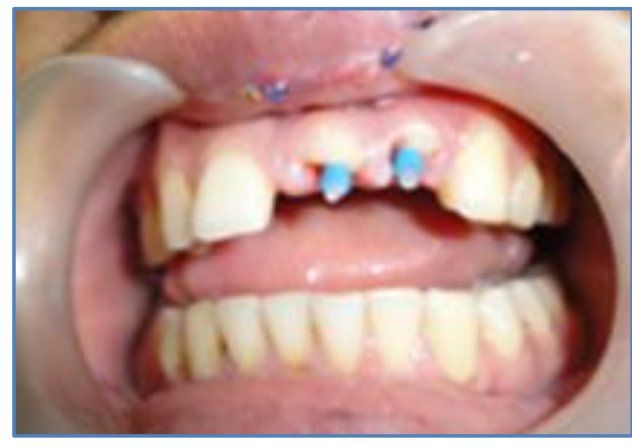

Fig. 5: Fibre post insertion

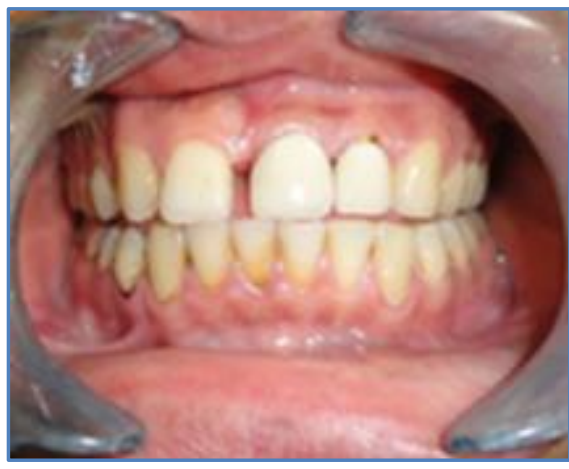

Fig. 7: Restored anterior teeth (post- operative)

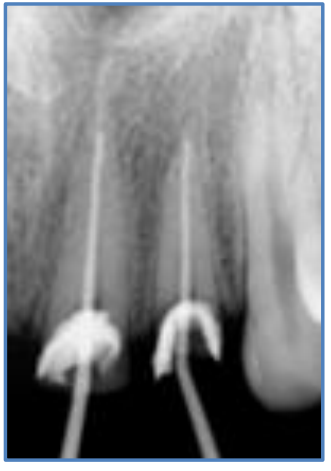

Fig. 4: x-ray showing length of GP point before obturation

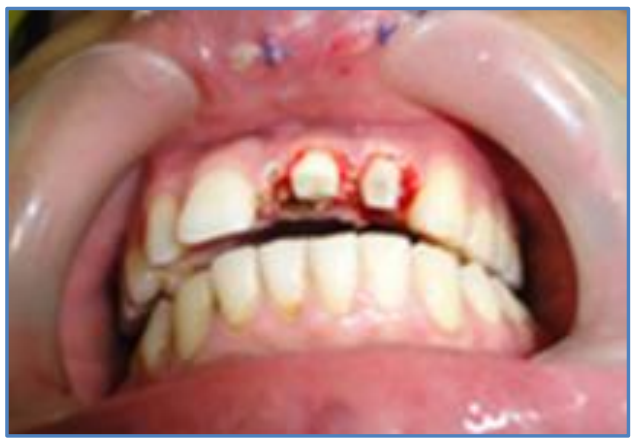

Fig. 6: Core preparation with crown lengthening using laser

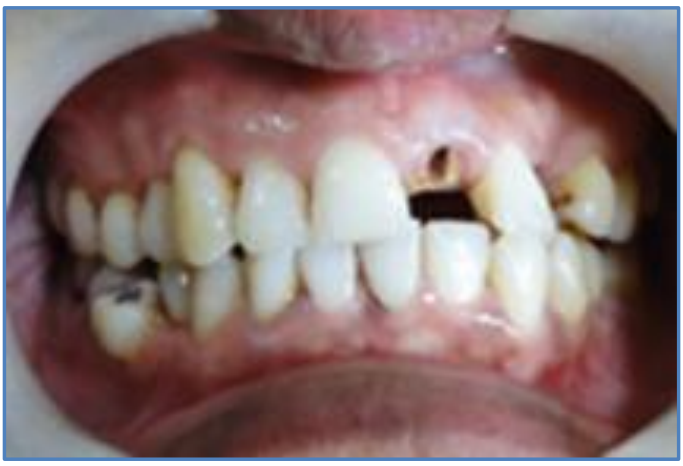

Fig. 8: Fractured Central incisor (pre- operative) 


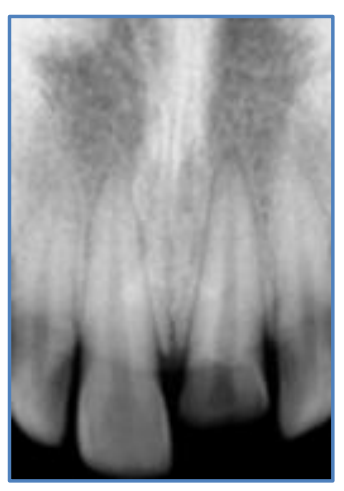

Fig. 9: pre-operative $x$ ray showing fractured cental incisor at CEJ

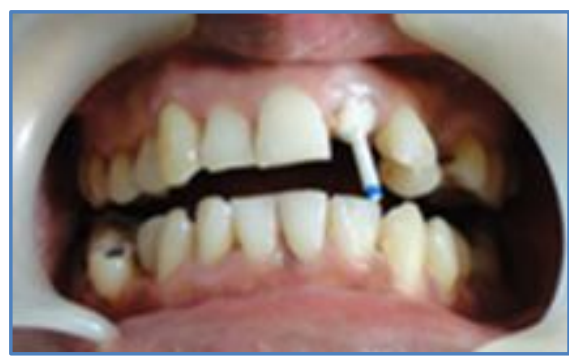

Fig. 11: Cementation of fibre- post in the RC treated Central incisor

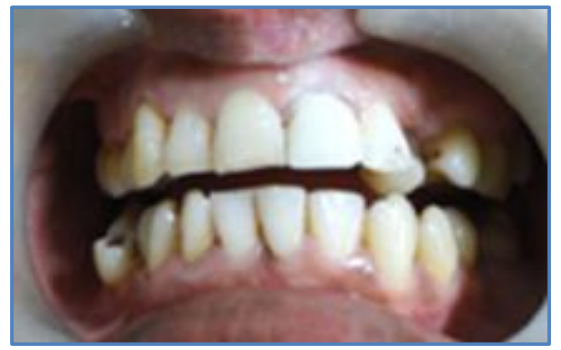

Fig. 13: Restored Central incisor

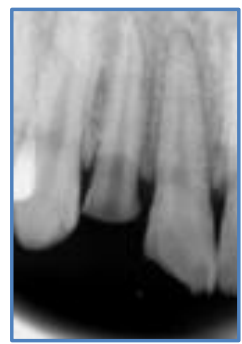

Fig. 15: pre-operative x-ray

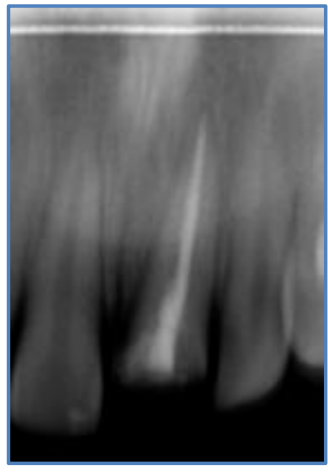

Fig. 10: X-ray after root canal treatment

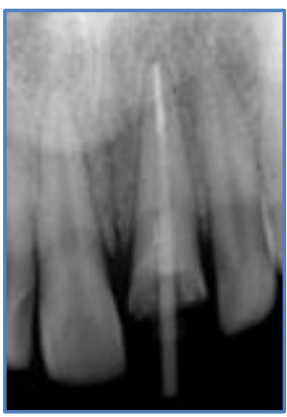

Fig. 12: X-ray showing the length of the fibre post in the canal

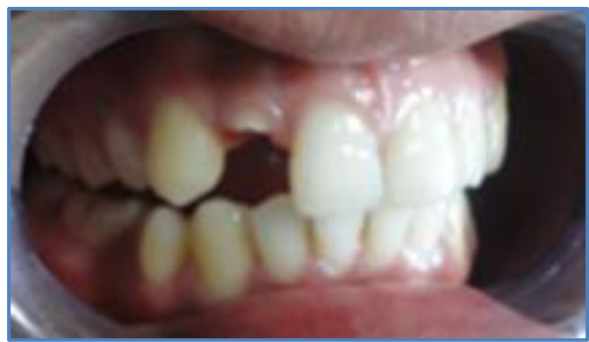

Fig. 14: Fractured lateral incisor

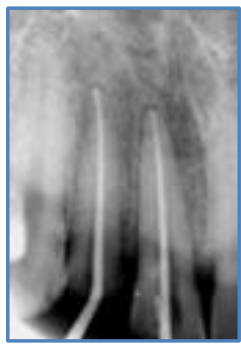

Fig. 16: x-ray showing length of GP point before obturation 


\section{CASE REPORT}

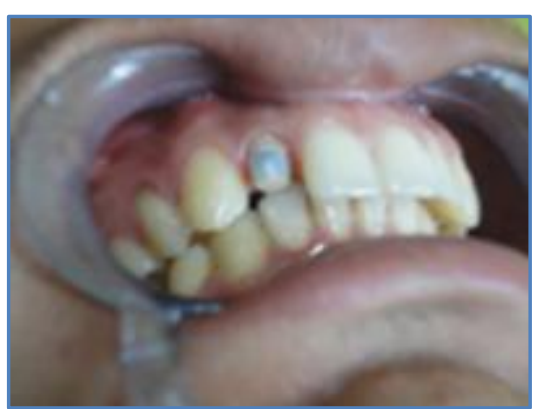

Fig. 17: Fibre-post cementation and core build up

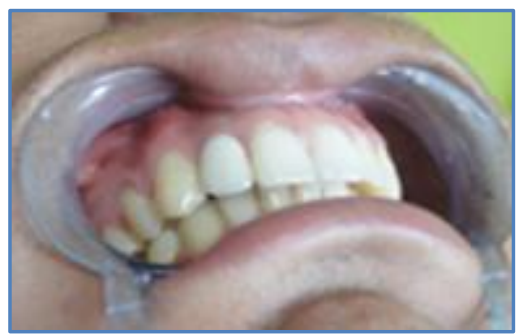

Fig. 19: Restored lateral incisor

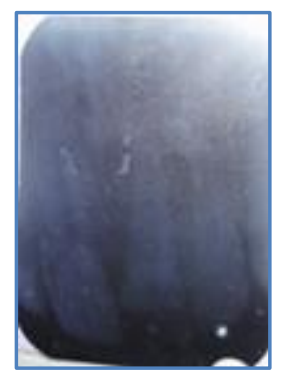

Fig. 21: Pre-operative $x$-ray

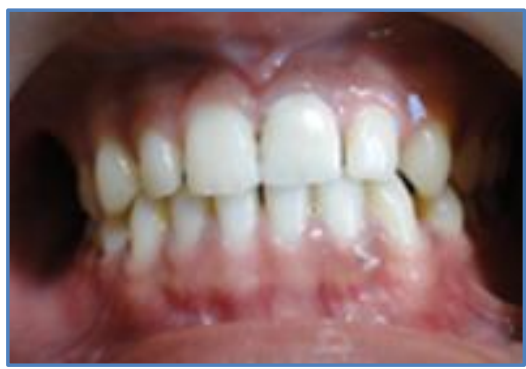

Fig. 23: Restored central incisor

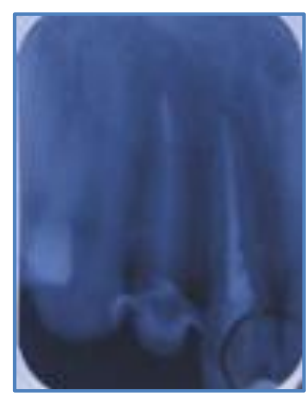

Fig. 18: X-ray showing the fibre post cemented in the lateral incisor

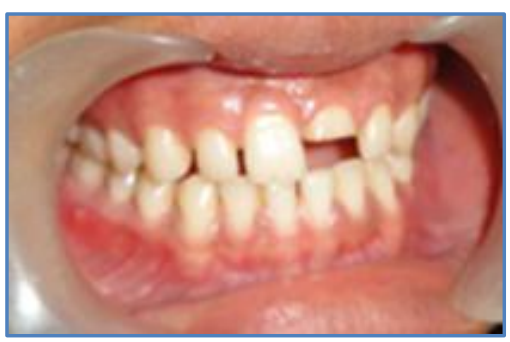

Fig. 20: Fractered central incisor

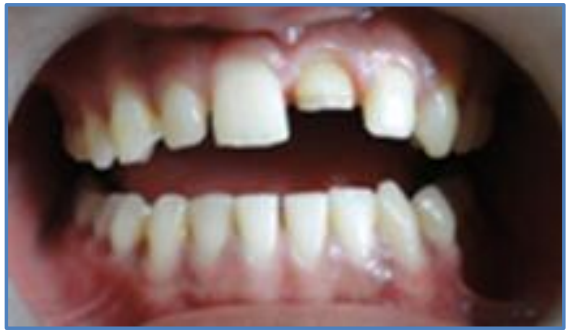

Fig. 22: Prepared tooth after fibre post cementation

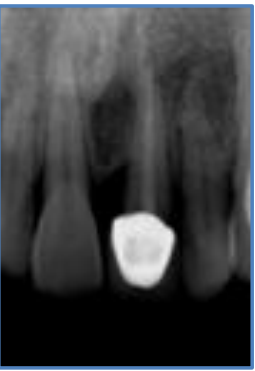

Fig. 24: Post -operative x-ray showing cemented fibre post with porcelain fused to ceramic crown 


\section{CASE REPORT}

\section{AUTHORS:}

1. N. Sukumar Singh

2. N. Satish Kumar Singh

3. Pinky Thangjam

\section{PARTICULARS OF CONTRIBUTORS:}

1. Assistant Professor, Department of Dentistry, Jawaharlal Nehru Institute of Medical Sciences, Porompat, Imphal.

2. Assistant Professor, Department of Dentistry, Jawaharlal Nehru Institute of Medical Sciences, Porompat, Imphal.

3. Dental Surgeon, Department of Dentistry, Jawaharlal Nehru Institute of Medical Sciences, Porompat, Imphal.

\section{NAME ADDRESS EMAIL ID OF THE} CORRESPONDING AUTHOR:

Dr. N. Satish Kumar Singh,

Nagamapal Singjubung Leirak, Imphal-West-795001.

Email: drnsatish@gmail.com

Date of Submission: 28/06/2014. Date of Peer Review: 29/06/2014. Date of Acceptance: 22/07/2014. Date of Publishing: 31/07/2014. 